\title{
SÉANCE DU 23 NOVEMBRE 1917
}

\author{
Présidence de M. P.-A. DANGeard.
}

Leeture est donnée duprocès-verbal de la dernière séance, dont la rédaction est adoptée.

Par suite des présentations faites dans cette séance sont proclamés membres de la Société :

MM. Lemée (Albert), receveur à Mamers (Sarthe),

Delafield (Mathurin L.), avenue Davel, 29, à Lausanne (Suisse), présentés l'un et l'autre par MM. Léveillé et Dangeard.

M. le Président annonce ensuite une nouvelle présentation.

Le Prince Bonaparte offre à la Société les fascicules 3 et 4 de ses Notes ptéridologiques et donne quelques explications à leur sujet.

M. F. Camus donne ensuite lecture des deux communications suivantes :

\section{Note sur un Carex présumé hybride des Carex acuta et paludosa}

par M. Émile GADEcEaU.

Au cours d'une herborisation faite le 10 juin dernier, en compagnie je notre confrère, M. Elie Cottereau, mon attention s'est portée sur un Carex dont le port me semblait celui du C. acuta, mais qui en différait, dès le premier examen, par la présence de trois stigmates au lieu de deux. Il croissait dans les prairies marécageuses au voisinage des $C$. acuta $\mathrm{L}$. et C. paludosa:̧ Good., à Guéville, près Rambouillet.

$\mathrm{Ce}$ Carex, est voisin de la plante décrite par M. Lambert, 
comme $C$. acuta $\times$ paludosa, sous le nom de C.auroniensis ${ }^{1}$. Il en diffère cependant par un certain nombre de caractères, en particulier par la forme des utricules : je dirais que le $C$. auroniensis tient davantage du $C$. acula que du C. paludosa, tandis que la plante de Guéville montre la tendance contraire.

Si tant est qu'on doive nommer chacune de ces formes hybrides, qui semblent avoir la même origine, je propose, pour celle-ci, le nom de $C$. Cottereaui.

Un examen attentif, comparatif, avec les parents présumés, m'a permis de préciser dans le tableau ci-dessous les principaux caractères des quatre formes visées.

\section{c. acuta L.}

Épillets males. . Linéaires, grêles.

Épillets femelles. Linéaires-allongés, l'inférieur assez longuement pédonculé, ordinairement penchẻs, au moinsl'inférieur; souvent mâles au sommet.

Utricules . . . Petits, obovales, à bec presque nul.

Sligmales... . Deux.

C. auroniensis Lambert.

Épillets mâles. . Cylindriques, étroits.

Épillets femelles. Sessiles, l'inférieur pédonculé, les supérieurs un peu étalés.

Utricules .... Petits, à bec court, entier.

Sligmales... Trois. c. paludosa Good.

Oblongs cylindriques, robustes.

Cylindriques, denses, dressés, sessiles, l'in. férieur courtement pédonculé.

Ovales-coniques, graduellement rétrécis en bec bifide, un peu allongé. rugúeux sous la loupe. Trois.

c. Cottereaui Nob.

Oblongs-cylindriques, assez robustes.

Sessiles, l'inférieur très courtement pédonculé, cylindriques, denses, dressés, mâles au sommet.

Assez gros, ovales, brusquement et nettement rétrécis en bec bifide assez court, rugueux sous la loupe.

Trois.

1. Bulletin Académie de Géogr. Lotanique, Le Mans, 1908, p. 341. 


\section{$2 \mathrm{BHL}$ Biodiversity Heritage Library}

Gadeceau, Émile. 1917. "Note sur un Carex présumé hybride des Carex acuta et paludosa." Bulletin de la Société botanique de France 64, 203-204. https://doi.org/10.1080/00378941.1917.10836034.

View This Item Online: https://www.biodiversitylibrary.org/item/8685

DOI: https://doi.org/10.1080/00378941.1917.10836034

Permalink: https://www.biodiversitylibrary.org/partpdf/159700

\section{Holding Institution}

Missouri Botanical Garden, Peter H. Raven Library

\section{Sponsored by}

Missouri Botanical Garden

\section{Copyright \& Reuse}

Copyright Status: Public domain. The BHL considers that this work is no longer under copyright protection.

This document was created from content at the Biodiversity Heritage Library, the world's largest open access digital library for biodiversity literature and archives. Visit BHL at https://www.biodiversitylibrary.org. 